\title{
The effect of a tin-containing fluoride mouth rinse on the bond between resin composite and erosively demineralised dentin
}

\author{
Simon Flury • Tamara Koch • Anne Peutzfeldt • \\ Adrian Lussi • Carolina Ganss
}

Received: 9 August 2011 / Accepted: 10 February 2012 /Published online: 15 March 2012

(C) Springer-Verlag 2012

\begin{abstract}
Objectives To evaluate the effect of a tin-containing fluoride $(\mathrm{Sn} / \mathrm{F})$ mouth rinse on microtensile bond strength $(\mu \mathrm{TBS})$ between resin composite and erosively demineralised dentin. Materials and methods Dentin of 120 human molars was erosively demineralised using a 10-day cyclic de- and remineralisation model. For 40 molars, the model comprised erosive demineralisation only; for another 40 , the model included treatment with a NaF solution; and for yet another 40 , the model included treatment with a $\mathrm{Sn} / \mathrm{F}$ mouth rinse. In half of these molars $(n=20)$, the demineralised organic matrix was continuously removed by collagenase. Silicon carbide paper-ground, non-erosively demineralised molars served as control $(n=20)$. Subsequently, $\mu$ TBS of Clearfil SE/Filtek Z250 to the dentin was measured, and failure mode was determined. Additionally, surfaces were evaluated using SEM and EDX.

Results Compared to the non-erosively demineralised control, erosive demineralisation resulted in significantly lower $\mu$ TBS regardless of the removal of demineralised organic matrix. Treatment with $\mathrm{NaF}$ increased $\mu \mathrm{TBS}$, but the level
\end{abstract}

Electronic supplementary material The online version of this article (doi:10.1007/s00784-012-0697-1) contains supplementary material, which is available to authorized users.

S. Flury $(\bowtie) \cdot$ T. Koch $\cdot$ A. Peutzfeldt $\cdot$ A. Lussi

Department of Preventive, Restorative and Pediatric Dentistry,

School of Dental Medicine, University of Bern,

Freiburgstrasse 7,

3010 Bern, Switzerland

e-mail: simon.flury@zmk.unibe.ch

C. Ganss

Department of Conservative and Preventive Dentistry,

Dental Clinic of the Justus Liebig University,

Schlangenzahl 14

35392 Giessen, Germany of $\mu$ TBS obtained by the non-erosively demineralised control was only reached when the demineralised organic matrix had been removed. The $\mathrm{Sn} / \mathrm{F}$ mouth rinse together with removal of demineralised organic matrix led to significantly higher $\mu$ TBS than did the non-erosively demineralised control. The $\mathrm{Sn} / \mathrm{F}$ mouth rinse yielded higher $\mu \mathrm{TBS}$ than did the $\mathrm{NaF}$ solution.

Conclusions Treatment of erosively demineralised dentin with a $\mathrm{NaF}$ solution or a $\mathrm{Sn} / \mathrm{F}$ mouth rinse increased the bond strength of resin composite.

Clinical relevance Bond strength of resin composite to eroded dentin was not negatively influenced by treatment with a tin-containing fluoride mouth rinse.

Keywords Erosion · Sodium fluoride · Stannous chloride $\cdot$ Collagenase $\cdot$ Adhesion

\section{Introduction}

In case of severe dental erosion (e.g. caused by eating disorders with chronic vomiting), symptomatic treatment is often indicated. One approach aims to prevent the further loss of tooth substance by forming acid-resistant mineral precipitations. Fluoride preparations containing monovalent or organic fluoride compounds may cause precipitation of calcium fluoride-like deposits on the tooth surface. However, these deposits probably offer limited protection against acid impacts as they readily dissolve at acidic $\mathrm{pH}$ [1]. In contrast, promising effects have been demonstrated with fluoride compounds containing polyvalent metal cations such as titanium fluoride [2] or stannous fluorides [3, 4]. The combination of stannous chloride and fluoride has been shown to be particularly effective against erosive mineral loss in the enamel and dentin [5]. 
On enamel, the application of tin-containing fluoride $(\mathrm{Sn} / \mathrm{F})$ solutions may result in the formation of various mineral salts such as $\mathrm{Sn}_{2}\left(\mathrm{PO}_{4}\right) \mathrm{OH}, \mathrm{Sn}_{3} \mathrm{~F}_{3} \mathrm{PO}_{4}$, and $\mathrm{Ca}\left(\mathrm{SnF}_{3}\right)_{2}$ [6-8], but little is known about interactions with dentin. Element analyses have shown that tin is deposited on dentin surfaces especially under erosive conditions and is incorporated both in the demineralised and mineralised tissue [9].

Although loss of tooth substance by erosion can be inhibited by appropriate non-invasive strategies, it is often necessary to restore the structural integrity and/or to reduce the hypersensitivity of eroded teeth with resin composites. A 3 -year randomized clinical study, however, has shown a higher failure rate of direct and indirect resin composite restorations in patients with tooth wear due to dental erosion than in patients without [10]. One possible explanation for the increased failure of these restorations is impaired adhesion of the resin composite to eroded dentin as compared to sound dentin, but studies on the issue are lacking. In addition, the influence of fluoride applications on bond strength of resin composites to eroded dentin has not been investigated so far. Particularly, Sn/F solutions are of interest as they alter the composition and solubility of dentin mineral, which could affect the properties of dentin as bonding substrate, and are currently among the most effective available products for daily home use.

The aim of this study was, therefore, to investigate the microtensile bond strength ( $\mu \mathrm{TBS}$ ) between resin composite and non-eroded dentin, erosively demineralised dentin, and erosively demineralised dentin subjected to a $\mathrm{NaF}$ solution or to a $\mathrm{Sn} / \mathrm{F}$ mouth rinse. To mimic eroded dentin with and without a layer of demineralised organic matrix, dentin was eroded according to two different protocols: without or with continuous removal of demineralised organic matrix by use of collagenase. The null hypothesis was that there would be no differences in $\mu$ TBS values between all groups.

Additionally, the dentin surfaces of all groups were qualitatively evaluated using scanning electron microscopy (SEM) and energy dispersive X-ray spectroscopy (EDX).

\section{Materials and methods}

Preparation of dentin specimens

Sound extracted human third molars were cleaned under tap water and stored in $0.5 \%$ chloramine solution at $4{ }^{\circ} \mathrm{C}$ until use. Then, the molars were embedded in circular moulds with self-curing acrylic resin (Paladur, Heraeus Kulzer $\mathrm{GmbH}$, Hanau, Germany) and ground with a grinding machine and silicon carbide (SiC) papers grit \#320 (Struers LaboPol-21/SiC \#320, Struers, Ballerup, Denmark) until the entire surface was in coronal dentin. The dentin surfaces were air-dried and carefully checked for absence of enamel.
Molars exhibiting exposure of the dental pulp were discarded. Finally, all molars were ground for $15 \mathrm{~s}$ with $\mathrm{SiC}$ papers grit \#500 (Struers LaboPol-21/SiC \#500, Struers), using a new $\mathrm{SiC}$ paper after the grinding of ten molars.

A final amount of 161 extracted human third molars was used. Twenty molars for $\mu$ TBS measurements and three molars for qualitative SEM and EDX evaluation were left untreated and served as non-erosively demineralised control (group 1). Twenty molars for $\mu$ TBS measurements and three molars for qualitative SEM and EDX evaluation of dentin surfaces were randomly allocated to each of the six groups of erosive demineralisation without and with continuous removal of demineralised organic matrix (groups $2 \mathrm{a} / \mathrm{b}, 3 \mathrm{a} / \mathrm{b}$, and $4 \mathrm{a} / \mathrm{b}$ ).

\section{Erosive demineralisation}

For erosive demineralisation, molars of groups $2 \mathrm{a} / \mathrm{b}, 3 \mathrm{a} / \mathrm{b}$, and $4 \mathrm{a} / \mathrm{b}$ were subjected to a cyclic de- and remineralisation procedure over a total of 10 days ( 5 days/week; 2 weeks). Molars were erosively demineralised with $0.05 \mathrm{M}$ citric acid solution (pH 2.3, anhydrous citric acid; Merck, Darmstadt, Germany) six times per day for $5 \mathrm{~min}$ under agitation in a shaking bath (30x/min, $25^{\circ} \mathrm{C}$; GFL Model 1083, Burgwedel, Germany). After the first erosive demineralisation and between the following erosive demineralisations, molars were stored in a remineralisation solution for $60 \mathrm{~min}$ (shaking bath, 30x/min, $25^{\circ} \mathrm{C}$; GFL Model 1083) according to Gerrard and Winter [11] (4.08 $\mathrm{mM} \mathrm{H}_{3} \mathrm{PO}_{4}, 20.10 \mathrm{mM} \mathrm{KCl}, 11.90 \mathrm{mM} \mathrm{Na}_{2} \mathrm{CO}_{3}$, and $1.98 \mathrm{mM} \mathrm{CaCl}_{2}$ with a $\mathrm{pH}$ of 6.7 ; all chemicals from Merck). For continuous removal of demineralised organic matrix (groups 2b, 3b, and 4b), 100 units/ml collagenase were added to the remineralisation solution $(\mathrm{pH} 7.4$; collagenase from Clostridium histolyticum type VII with a collagen removal activity of 1.680 units $/ \mu \mathrm{g}$, solid at $25^{\circ} \mathrm{C}$ at $\mathrm{pH} 7.5$ in the presence of calcium ions; Sigma Aldrich, St. Louis, MO, USA). Over the weekend, molars were stored in a humid chamber $\left(100 \%\right.$ relative humidity) at $4^{\circ} \mathrm{C}$. Solutions were renewed at the beginning of each experimental day. Groups $2 \mathrm{a} / \mathrm{b}$ underwent erosive demineralisation only. In groups $3 \mathrm{a} / \mathrm{b}$, a $\mathrm{NaF}$ solution (NaF $500 \mathrm{ppm}$, adjusted to $\mathrm{pH} 4.5$ with $1 \%$ $\mathrm{HCl}$ ), and in groups $4 \mathrm{a} / \mathrm{b}, \mathrm{a} \mathrm{Sn} / \mathrm{F}$ mouth rinse $[125 \mathrm{ppm} \mathrm{F}$ as amine fluoride (AmF), $375 \mathrm{ppm} \mathrm{F}$ as $\mathrm{NaF}$, and $800 \mathrm{ppm} \mathrm{Sn}$ as $\mathrm{SnCl}_{2}, \mathrm{pH} 4.5$; Elmex ${ }^{\circledR}$ erosion protection, GABA International, Therwil, Switzerland] was used for $2 \mathrm{~min}$ after the first and the last demineralisation period. Before transfer to a new solution, molars were rinsed for $1 \mathrm{~min}$ with tap water.

Microtensile bond strength measurements and failure mode determination

Subsequently, the two-bottle self-etch adhesive system Clearfil SE (Kuraray, Okayama, Japan) was applied on the dentin surface of the 20 molars in each group according to 
manufacturer's instructions (primer 10-methacryloyloxydecyl dihydrogen phosphate (MDP), 2-hydroxyethyl methacrylate (HEMA), hydrophilic dimethacrylate, dl-camphorquinone, water; Lot No. 00965AA; bond MDP, HEMA, bis-phenol A diglycidylmethacrylate (Bis-GMA), hydrophobic dimethacrylate, dl-camphorquinone, silanated colloidal silica; Lot No. 01387AA). After adhesive treatment, the molars were built up in two layers of $2 \mathrm{~mm}$ each with a resin composite (Filtek Z250, 3 M ESPE, St. Paul, MN, USA; shade A4, Lot No. N183899). Each layer of resin composite was light-cured for $20 \mathrm{~s}$, and all light-curing was performed with an LED lightcuring unit (Demi, Kerr Corporation, Middleton, WI, USA). Light power density was verified to be at least $1,000 \mathrm{~mW} / \mathrm{cm}^{2}$ at the beginning and end of each day of specimen preparation with a radiometer (Demetron LED Radiometer, Kerr Corporation). The molars with the resin composite build-ups were stored for $24 \mathrm{~h}$ in $100 \%$ humidity at $37^{\circ} \mathrm{C}$.

After storage, the molars were sectioned with an electronically programmable diamond saw under water-cooling (Struers Accutom-5 with Struers diamond cut-off wheel 330CA, Struers) perpendicularly to the adhesive interface in both $x$ and $y$ directions to obtain nine sticks from the most central part of each molar. Four sticks per molar were randomly selected for measurement of $\mu$ TBS. In the rare cases of pretesting failure (13 pretesting failures $/ 560$ final sticks), one of the remaining five sticks of the same tooth was used as replacement. In order to monitor the size and to calculate the bonding surface (BSU $\left(\mathrm{mm}^{2}\right)$ ) of each stick, width and breadth of the sticks were measured with a digital caliper (Mitutoyo IP 65, Kawasaki, Japan; mean width (standard deviation), $1.05 \mathrm{~mm}(0.03)$; mean breadth (standard deviation), $1.05 \mathrm{~mm}(0.02)$ ). Then, the sticks were fixed by their ends to notched Ciucchi's jigs mounted in a universal testing machine (Syndicad TC-550, Syndicad Dental Research, Munich, Germany) with a low viscosity resin (Heliobond, Ivoclar Vivadent AG, Schaan, Liechtenstein). The sticks were stressed in tension at a crosshead speed of $1.0 \mathrm{~mm} / \mathrm{min}$ until fracture, and the maximum force $\left(F_{\max }(\mathrm{N})\right)$ was recorded. The $\mu$ TBS values $(\mathrm{MPa})$ were calculated according to the formula, $\mu \mathrm{TBS}=F_{\max } /$ BSU.

Additionally, the failure mode of each stick was stereomicroscopically determined at $45 \times$ magnification (Leica ZOOM 2000, Leica, Buffalo, NY, USA) and classified into one of the five following categories: (1) cohesive failure in dentin, (2) adhesive failure between adhesive system and dentin, (3) mixed adhesive failure (failure modes 2 and 4), (4) adhesive failure between adhesive system and resin composite, and (5) cohesive failure in resin composite.

\section{Qualitative SEM and EDX evaluation of dentin surfaces}

Three molars from each group were mounted on aluminium stubs and dehydrated in a desiccator for 5 days and then sputter-coated with gold/palladium $(100 \mathrm{~s}, 50 \mathrm{~mA})$ using a sputtering device (Balzers SCD 050, Balzers, Liechtenstein). Dentin surfaces were evaluated under an SEM (JSM-6510, Jeol, Tokyo, Japan), and micrographs of 5,000 $\times$ magnification were made.

For EDX, the acceleration voltage of the SEM was set to $15 \mathrm{kV}$, and EDX spectra were collected using a Silicon Drift Droplet Detector (X-Flash Detector 410-M, Bruker Nano $\mathrm{GmbH}$, Berlin, Germany). Count rates were $\sim 1 \mathrm{kcps}$ and remained constant during the measurements, indicating that neither contamination nor loss of mass affected the results.

\section{Statistical analysis of $\mu$ TBS values}

Out of the four $\mu$ TBS values obtained per molar, a mean $\mu$ TBS value was calculated. Therefore, $20 \mu$ TBS values per group were used for statistical analysis with a nonparametrical ANOVA model for two fixed factors according to Brunner and Munzel [12] followed by Wilcoxon rank sum tests and Bonferroni-Holm adjustment for multiple testing. The main statistical analysis was performed with $\mathrm{R}$ version 2.9.1 (The R Foundation for Statistical Computing, Vienna, Austria; www.R-project.org).

The $\mu$ TBS data of preliminary tests had been statistically analysed with NCSS/PASS 2005 (NCSS, Kaysville, UT, USA) for sample size determination after the level of significance had been set at $\alpha=0.05$.

\section{Results}

Microtensile bond strength measurements and failure mode determination

The $\mu$ TBS values are shown in Fig. 1, and the $p$ values of group comparisons are given in Table 1 . The nonparametrical ANOVA model showed significant differences between the groups $(p<0.0001)$ and a significant effect of continuous removal of demineralised organic matrix $(p<$ $0.0001)$ with significantly higher $\mu$ TBS values when the demineralised organic matrix had been removed. No statistically significant interaction was found between continuous removal of demineralised organic matrix and the different groups, indicating that continuous removal of demineralised organic matrix had the same effect on $\mu$ TBS values in groups 2, 3, and 4 .

Compared to the non-erosively demineralised control (group 1), the erosive demineralisation resulted in significantly lower $\mu$ TBS values regardless of the removal of demineralised organic matrix (groups $2 \mathrm{a} / \mathrm{b}$ ). Treatment with $\mathrm{NaF}$ (groups $3 \mathrm{a} / \mathrm{b}$ ) increased $\mu \mathrm{TBS}$ values, but the $\mu \mathrm{TBS}$ values of the non-erosively demineralised control was only reached when the demineralised organic matrix had been 
Fig. 1 Microtensile bond strength values of the different groups (median, lower/first and upper/third quartile, and minima/maxima): (a) no continuous removal of demineralised organic matrix and (b) continuous removal of demineralised organic matrix

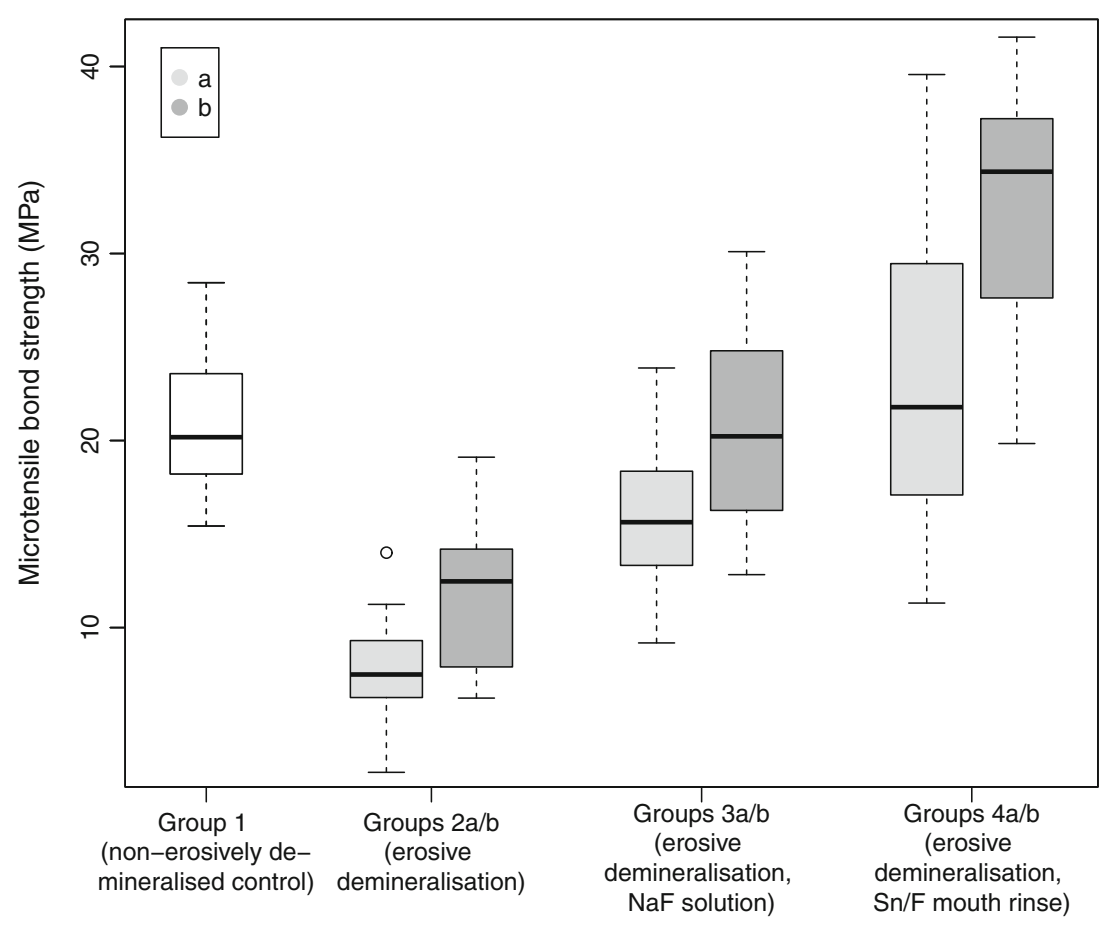

removed (group 3b). In contrast, the application of the $\mathrm{Sn} / \mathrm{F}$ mouth rinse together with removal of demineralised organic matrix (Group 4b) led to significantly higher $\mu$ TBS-values compared to the non-erosively demineralised control (Group 1). Compared to erosive demineralisation only (groups $2 \mathrm{a} / \mathrm{b}$ ), treatment with both $\mathrm{NaF}$ solution (groups $3 \mathrm{a} / \mathrm{b}$ ) and $\mathrm{Sn} / \mathrm{F}$ mouth rinse (groups $4 \mathrm{a} / \mathrm{b}$ ) increased $\mu$ TBS values regardless of the removal of demineralised organic matrix; the $\mathrm{Sn} / \mathrm{F}$ mouth rinse yielding higher $\mu \mathrm{TBS}$ values than the $\mathrm{NaF}$ solution.

The distribution of failure modes is shown in Table 2 . The non-erosively demineralised control (group 1) presented a majority of mixed adhesive failures followed by adhesive failures between adhesive system and dentin. The predominant failure mode of groups $2 \mathrm{a} / \mathrm{b}$ and $3 \mathrm{a}$ was adhesive failure between adhesive system and dentin. In group $3 b$ and groups $4 \mathrm{a} / \mathrm{b}$, the predominant failure mode was mixed adhesive failure. Continuous removal of demineralised organic matrix (groups $2 b, 3 b$, and $4 b$ ) showed an increased amount of both mixed adhesive failures and adhesive failures between adhesive system and resin composite when compared to groups $2 \mathrm{a}, 3 \mathrm{a}$, and $4 \mathrm{a}$ (without continuous removal of demineralised organic matrix).

\section{Qualitative SEM and EDX evaluation of dentin surfaces}

Qualitative SEM evaluation revealed quite a similar dentin surface for all three molars in each group. Representative micrographs are shown in Fig. 2.

Table 1 Comparison of microtensile bond strength values by Wilcoxon rank sum tests

\begin{tabular}{|c|c|c|c|c|c|c|}
\hline & $\begin{array}{l}\text { Group 2a (erosive } \\
\text { demineralisation) }\end{array}$ & $\begin{array}{l}\text { Group 2b (erosive } \\
\text { demineralisation) }\end{array}$ & $\begin{array}{l}\text { Group } 3 a \text { (erosive } \\
\text { demineralisation, } \\
\text { NaF solution) }\end{array}$ & $\begin{array}{l}\text { Group } 3 b \text { (erosive } \\
\text { demineralisation, } \\
\text { NaF solution) }\end{array}$ & $\begin{array}{l}\text { Group } 4 \mathrm{a} \text { (erosive } \\
\text { demineralisation, } \\
\mathrm{Sn} / \mathrm{F} \text { mouth rinse) }\end{array}$ & $\begin{array}{l}\text { Group } 4 b \text { (erosive } \\
\text { demineralisation, } \\
\text { Sn/F mouth rinse) }\end{array}$ \\
\hline $\begin{array}{l}\text { Group } 1 \text { (non-erosively } \\
\text { demineralised control) }\end{array}$ & $<0.0001 *$ & $<0.0001 *$ & $0.0002 *$ & 0.8498 & 0.4652 & $<0.0001^{*}$ \\
\hline Group $2 \mathrm{a}$ & - & $0.0018^{*}$ & $<0.0001^{*}$ & $<0.0001^{*}$ & $<0.0001^{*}$ & $<0.0001^{*}$ \\
\hline Group $2 b$ & - & - & $0.0012 *$ & $<0.0001^{*}$ & $<0.0001^{*}$ & $<0.0001^{*}$ \\
\hline Group 3a & - & - & - & $0.0030^{*}$ & $0.0022 *$ & $<0.0001^{*}$ \\
\hline Group 3b & - & - & - & - & 0.3834 & $<0.0001^{*}$ \\
\hline Group 4a & - & - & - & - & - & $0.0004 *$ \\
\hline
\end{tabular}

Groups 2a, 3a, and 4a, no continuous removal of demineralised organic matrix; groups $2 b, 3 b$, and $4 b$, continuous removal of demineralised organic matrix

$p$-values marked with * show significant differences between groups after Bonferroni-Holm adjustment for multiple testing 
Table 2 Failure mode determination

\begin{tabular}{|c|c|c|c|c|c|}
\hline \multirow{2}{*}{$\begin{array}{l}\text { Groups }(n=20 \text { molars } \\
\text { per group) }\end{array}$} & \multicolumn{5}{|c|}{ Failure mode ( 80 sticks, 4 per molar) } \\
\hline & $\begin{array}{l}\text { (1) Cohesive failure } \\
\text { in dentin }(\%)\end{array}$ & $\begin{array}{l}\text { (2) Adhesive failure } \\
\text { between adhesive } \\
\text { system and dentin (\%) }\end{array}$ & $\begin{array}{l}\text { (3) Mixed adhesive } \\
\text { failure (failure modes } \\
2 \text { and } 4)(\%)\end{array}$ & $\begin{array}{l}\text { (4) Adhesive failure } \\
\text { between adhesive system } \\
\text { and resin composite }(\%)\end{array}$ & $\begin{array}{l}\text { (5) Cohesive } \\
\text { failure in resin } \\
\text { composite (\%) }\end{array}$ \\
\hline $\begin{array}{l}\text { Group } 1 \text { (non-erosively } \\
\text { demineralised control) }\end{array}$ & 1 & 35 & 59 & 5 & 0 \\
\hline $\begin{array}{l}\text { Group 2a (erosive } \\
\text { demineralisation) }\end{array}$ & 0 & 83 & 17 & 0 & 0 \\
\hline $\begin{array}{l}\text { Group } 2 \mathrm{~b} \text { (erosive } \\
\text { demineralisation) }\end{array}$ & 0 & 63 & 36 & 1 & 0 \\
\hline $\begin{array}{l}\text { Group 3a (erosive } \\
\text { demineralisation, } \\
\text { NaF solution) }\end{array}$ & 0 & 54 & 46 & 0 & 0 \\
\hline $\begin{array}{l}\text { Group } 3 b \text { (erosive } \\
\text { demineralisation, } \\
\text { NaF solution) }\end{array}$ & 0 & 34 & 54 & 12 & 0 \\
\hline $\begin{array}{l}\text { Group 4a (erosive } \\
\text { demineralisation, } \\
\text { Sn/F mouth rinse) }\end{array}$ & 1 & 34 & 50 & 14 & 1 \\
\hline $\begin{array}{l}\text { Group } 4 \mathrm{~b} \text { (erosive } \\
\text { demineralisation, } \\
\mathrm{Sn} / \mathrm{F} \text { mouth rinse) }\end{array}$ & 0 & 25 & 59 & 15 & 1 \\
\hline
\end{tabular}

Groups 2a, 3a, and 4a, no continuous removal of demineralised organic matrix; groups $2 \mathrm{~b}, 3 \mathrm{~b}$, and $4 \mathrm{~b}$, continuous removal of demineralised organic matrix

The non-erosively demineralised dentin surfaces showed typical signs of a smear layer with parallel undulations caused by grinding with no visible tubules (Fig. 2A). In the groups with erosive demineralisation, the smear layer had been entirely removed, and open tubules were apparent on all surfaces (Fig. 2B-G). The peritubular dentin was absent except after treatment with $\mathrm{Sn} / \mathrm{F}$ mouth rinse and continuous removal of the demineralised organic matrix (group 4b), and the intertubular areas appeared more or less amorphous with no obvious differences between groups.

The EDX spectra revealed distinct differences between groups treated with or without continuous removal of demineralised organic matrix. In groups $2 \mathrm{a}, 3 \mathrm{a}$, and $4 \mathrm{a}$ without continuous removal of demineralised organic matrix, the dentin surface was fully demineralised with only small peaks for $\mathrm{Ca}$ and $\mathrm{P}$ (Fig. 3B, D, F). In contrast, in groups $2 \mathrm{~b}, 3 \mathrm{~b}$, and $4 \mathrm{~b}$ with continuous removal of demineralised organic matrix, much more mineral with distinct peaks for $\mathrm{Ca}$ and $\mathrm{P}$ was present (Fig. 3C, E, G). In groups $4 \mathrm{a} / \mathrm{b}$ (treated with the $\mathrm{Sn} / \mathrm{F}$ mouth rinse), tin was clearly detected in group $4 \mathrm{~b}$ with continuous removal of demineralised organic matrix, but not in group 4a without continuous removal of demineralised organic matrix.

\section{Discussion}

Clinically, restoring eroded teeth is particularly indicated in cases with severe loss of tooth substance. The present study aimed to simulate such clinical conditions by creating severe erosive demineralisation as described in previous studies [9, 13]. In vitro, erosive demineralisation with acids (of clinically relevant amounts and time durations) results in a dissolution of mineral with persisting organic matrix [14]. With the model of cyclic de- and remineralisation used in the present study, loss of mineral in the order of $90 \mu \mathrm{m}$ occurs [15], thus resulting in a broad zone of demineralised organic matrix on the dentin surfaces. These dentin surfaces appear wet, soft, and resilient-a pattern which is not observed clinically. Knowledge about the structure of eroded dentin in vivo is sparse, but it can be assumed that proteolytic intraoral enzymes continuously remove demineralised dentin from the surface. As it is not clear how fast and how complete these proteolytic effects are, dentin in the present study was eroded according to two different protocols: without or with continuous removal of demineralised organic matrix by use of collagenase, which has previously been shown to be effective [9].

Adhesion of resin composite to dentin depends on the interaction of the adhesive system and the dentin surface and depends on the ability of the adhesive system (mainly of the primer) to penetrate dentin, including the formation of a future hybrid layer. The adhesion mechanism is assumed to be predominantly micromechanical, but also, physicochemical interactions are possible [16]. The adhesive system used in the present study (Clearfil SE) is a two-bottle selfetch adhesive system and can be considered as wellinvestigated and well-documented [17, 18]. The fact that 
Fig. 2 Micrographs of the scanning electron microscopy for qualitative evaluation of dentin surfaces (groups a, no continuous removal of demineralised organic matrix; groups b, continuous removal of demineralised organic matrix)
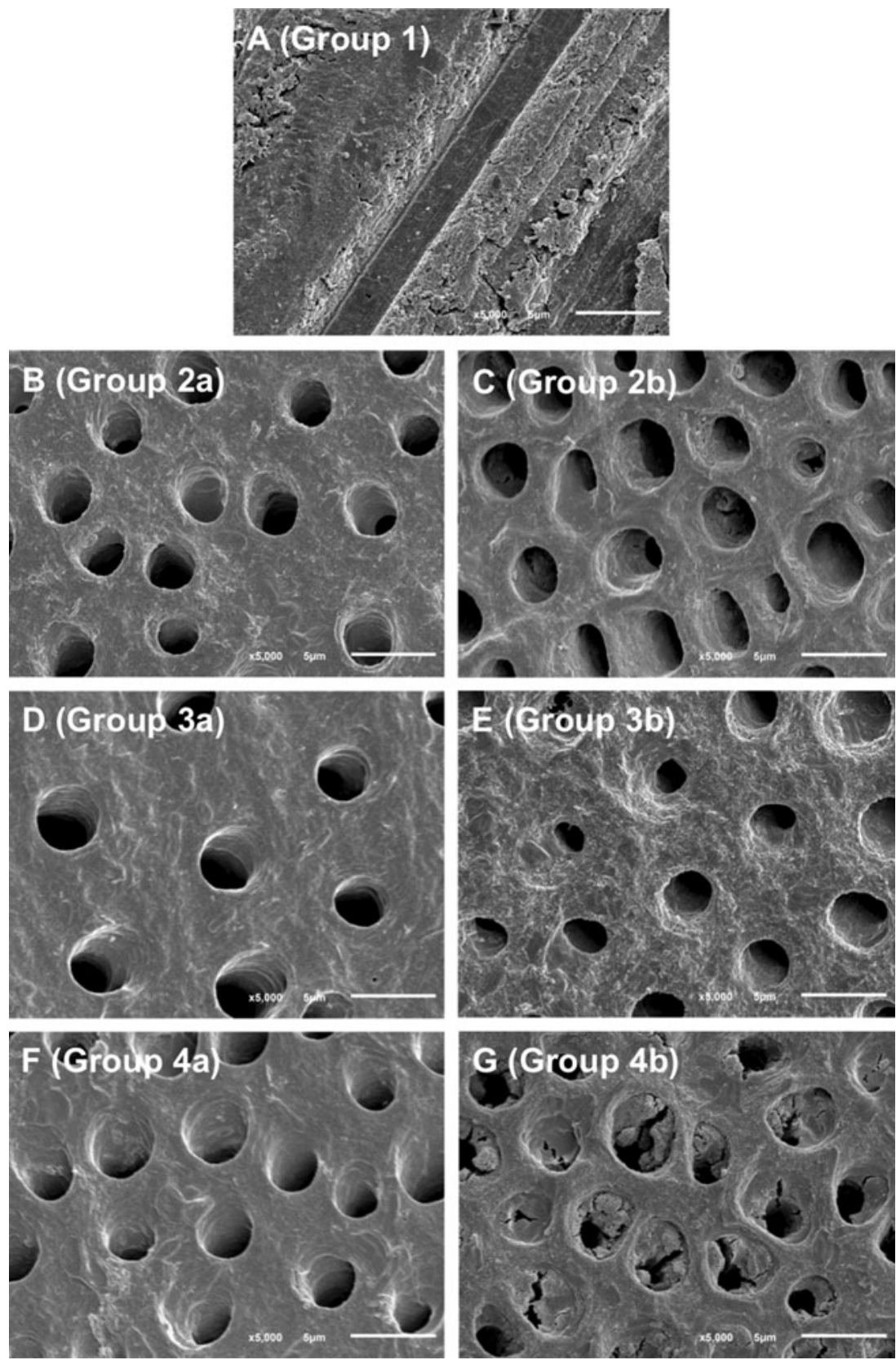

with the Clearfil SE adhesive system, phosphoric acid etching is not performed, and primer and bond are applied without extensive manipulation (e.g. by "brushing in" of the primer) might be of advantage, because phosphoric acid etching and brushing in of the primer might alter the structure of erosively demineralised dentin and its organic matrix uncontrollably. Clearfil SE contains an acidic phosphate monomer (MDP) which has been demonstrated to be capable of bonding to hydroxyapatite (HAP) [19], leaving the option for not only micromechanical but also chemical bonding to tooth substance. Proposed interaction of MDP to HAP is ionic bonding of phosphate groups to calcium or covalent bonding via condensation with the $\mathrm{PO}_{4}{ }^{3-}$ ions of HAP. The MDP monomers are adsorbed to HAP inducing the dissolution of calcium and phosphate followed by the deposition of MDP-calcium salts and calcium phosphate [20]. MDP dissolves calcium from HAP and interacts as calcium salt with dentin structures. A study investigating the intermolecular interaction of MDP and its calcium salt with collagen revealed that both forms might have different conformational states and docking sites [21], both contributing to the bonding of MDP.

Normally, adhesive systems are applied on sound dentin covered with a smear layer or on sclerotic dentin (e.g. of wedge-shaped defects). In the present study, however, the substrate for bonding was erosively demineralised dentin with the organic matrix being demineralised to various degrees as confirmed using EDX. Thus, the question arises, 
Fig. 3 Spectra of the energy dispersive X-ray spectroscopy for qualitative evaluation of dentin surfaces (groups a, no continuous removal of demineralised organic matrix; groups $\mathbf{b}$, continuous removal of demineralised organic matrix)
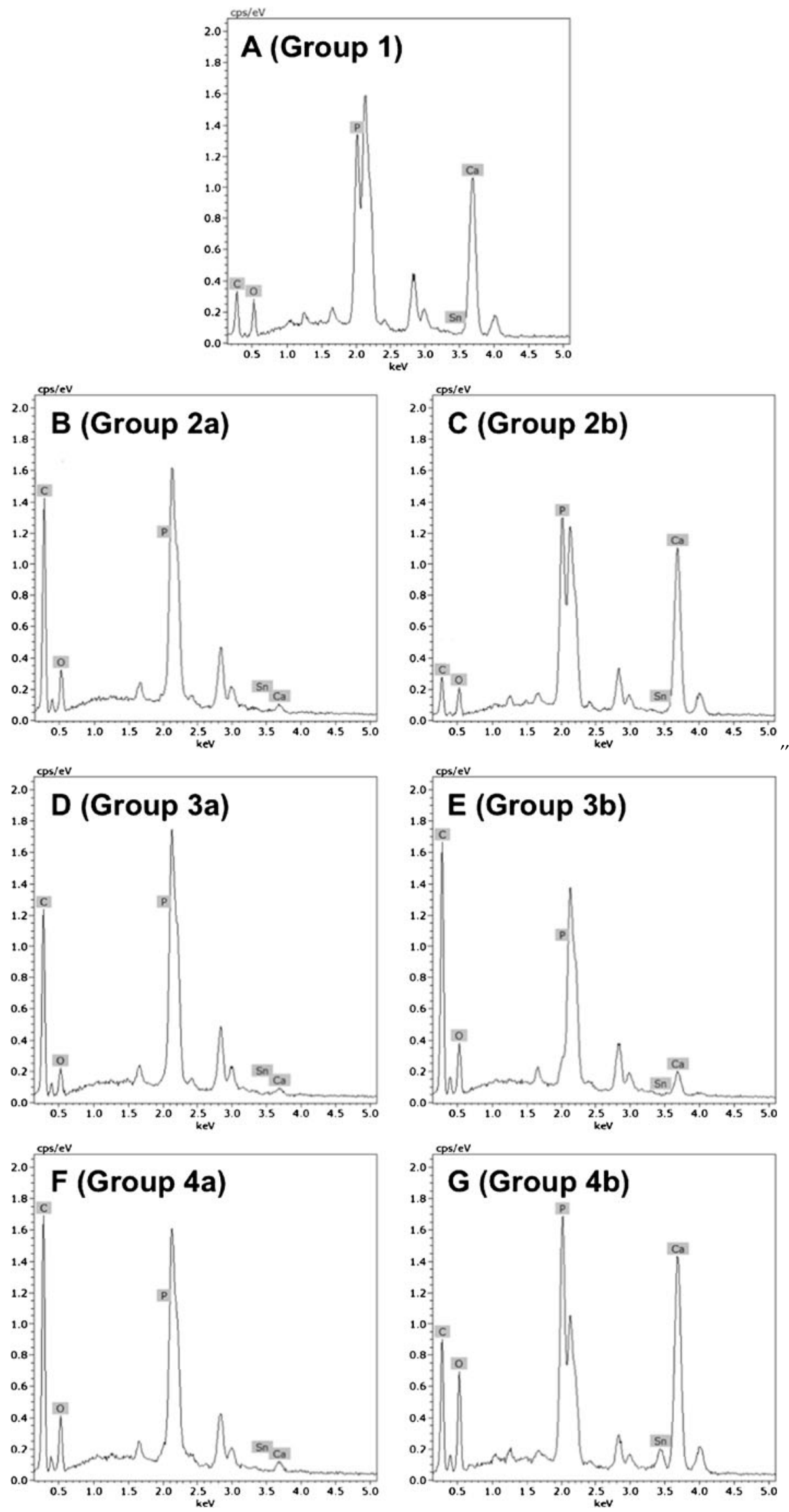
how the interaction between Clearfil SE and the respective substrates is characterised.

Regarding the fully demineralised organic matrix, it is well conceivable that due to the hydrophilic properties of MDP, the primer penetrates quite deeply into the organic matrix. It is, however, also reasonable to assume that the penetration is incomplete, and that the bond strength values observed represent the tensile strength of the adhesive system to the remaining unpenetrated demineralised dentin. Thus, it is not surprising that the bond strength values were significantly lower than to the non-erosively demineralised control. After treatment with the $\mathrm{NaF}$ solution, significantly higher bond strength values were found. It has been shown that a $500 \mathrm{ppm} \mathrm{NaF}$ solution reduced the erosive mineral loss in dentin by about $40 \%$ [15]. This suggests that in the present study, as well, the demineralised organic matrix was much thinner after NaF treatment than after erosive demineralisation only. Consequently, the penetration of the adhesive system may be more advanced, thus increasing bond strength. With the $\mathrm{Sn} / \mathrm{F}$ mouth rinse, a reduction of erosive mineral loss by about $50 \%$ can be expected [15], resulting in a thickness of the demineralised organic matrix similar to that obtained after treatment with the NaF solution. Interestingly, however, the bond strength values were markedly higher after $\mathrm{Sn} / \mathrm{F}$ treatment than after application of $\mathrm{NaF}$. This may be explained by the fact that the organic matrix, though fully demineralised, retains tin to a certain extent [9]. Tin ions could occupy negatively charged bonding sites such as phosphate groups in the organic matrix, thus making the collagen structure less polar and more accessible for the adhesive. Also, tin ions could function as calcium in the MDP-calcium salt and promote "docking" of MDP to collagen. Finally, a further mode of action is conceivable. Within the organic matrix and its collagen network, proteoglycans function as regulators for the three-dimensional arrangement of the collagen network and for the spacing of the collagen fibrils [22]. The removal of proteoglycans has been shown to enlarge spaces between collagen fibrils and to increase bond strength values [23], and the authors speculated that these empty intercollagen spaces are more accessible to the adhesive. Proteoglycans can be removed by enzymes [23] but also by acids at low $\mathrm{pH}$ or relatively highly concentrated $\mathrm{MgCl}(0.5 \mathrm{M})$ [22]. It can be speculated that the $\mathrm{Sn} / \mathrm{F}$ mouth rinse containing $\mathrm{SnCl}_{2}$ exhibits similar effects, resulting in an enhanced infiltration of the adhesive system.

In the groups with continuous removal of the demineralised organic matrix, the dentin surfaces were much more mineralised. The SEM micrographs and EDX spectra revealed more or less fully mineralised intertubular dentin with open tubules. These surfaces might approximate the clinical structure of active erosive lesions under severe dental erosion (e.g. caused by eating disorders with chronic vomiting) and the potential continuous removal of organic matrix by the multitude of salivary [24] or gastric proteolytic enzymes [25]. In all groups with continuous removal of demineralised organic matrix, bond strength values were higher than those in the groups without removal.

In the erosively demineralised groups without any fluoride treatment, bond strength values did not reach those of the non-erosively demineralised control, although the degree of mineralisation was similar. It is well conceivable that the removal of collagen under the severe erosive conditions used in the present study was not complete, leaving amorphous remnants of organic material on the surface. This is supported by the finding that in two thirds of the molars, the failure mode was adhesive failure between adhesive system and dentin. After treatment with the $\mathrm{NaF}$ solution, bond strength values were higher than those of the erosively demineralised groups. This might be due to a more complete removal of the demineralised organic matrix with slower erosive demineralisation when treated with the $\mathrm{NaF}$ solution. The treatment with the $\mathrm{Sn} / \mathrm{F}$ mouth rinse resulted in the highest bond strength values. It has been shown that tin is retained on and in dentin after application of $\mathrm{Sn} / \mathrm{F}$ solutions and continuous removal of demineralised organic matrix [9], which was confirmed in the present study. The exact erosion protective mechanism of tin is unknown, but it can be speculated that various forms of $\mathrm{Sn} / \mathrm{F}$ salts make the remaining mineral acid resistant. This speculation is confirmed by the SEM micrograph of the dentin surface after treatment with $\mathrm{Sn} / \mathrm{F}$ mouth rinse and continuous removal of the demineralised organic matrix, in that, peritubular dentin is clearly visible indicating an overall higher mineral content. Whether the high bond strength values are due to the amount of mineral or due to adhesion to tin-supported HAP being superior than adhesion to HAP alone, is subject for further research. Finally, some of the discussed adhesion mechanisms and interactions may only be valid for the MDP-containing adhesive system Clearfil SE. At this point, it therefore remains to be investigated how other adhesive systems interact with eroded dentin as well as with eroded dentin treated with $\mathrm{NaF}$ or $\mathrm{Sn} / \mathrm{F}$ solutions and mouth rinses.

Acknowledgements The authors would like to thank 3 M ESPE, Germany and Kuraray Europe, Germany for providing the materials needed. Furthermore, we thank S. Hayoz and Prof. Dr. J. Hüsler, Institute of Mathematical Statistics and Actuarial Science, University of Bern, for statistical analyses.

Conflicts of interest The authors declare no conflicts of interest, real or perceived, financial or non-financial.

\section{References}

1. Rølla G (1988) On the role of calcium fluoride in the cariostatic mechanism of fluoride. Acta Odontol Scand 46:341-345 
2. Wiegand A, Magalhães AC, Attin T (2010) Is titanium tetrafluoride (TiF4) effective to prevent carious and erosive lesions? A review of the literature. Oral Health Prev Dent 8:159-164

3. Ganss C, Schlueter N, Hardt M, Schattenberg P, Klimek J (2008) Effect of fluoride compounds on enamel erosion in vitro: a comparison of amine, sodium and stannous fluoride. Caries Res 42:2-7

4. Ganss C, Lussi A, Sommer N, Klimek J, Schlueter N (2010) Efficacy of fluoride compounds and stannous chloride as erosion inhibitors in dentine. Caries Res 44:248-252

5. Ganss C, Neutard L, von Hinckeldey J, Klimek J, Schlueter N (2010) Efficacy of a tin/fluoride rinse: a randomized in situ trial on erosion. J Dent Res 89:1214-1218

6. Cooley WE (1961) Reactions of tin (II) and fluoride ions with etched enamel. J Dent Res 40:1199-1210

7. Krutchkoff DJ, Jordan TH, Wei SH, Nordquist WD (1972) Surface characterization of the stannous fluoride-enamel interaction. Arch Oral Biol 17:923-930

8. Babcock FD, King JC, Jordan TH (1978) The reaction of stannous fluoride and hydroxyapatite. J Dent Res 57:933-938

9. Ganss C, Hardt M, Lussi A, Cocks AK, Klimek J, Schlueter N (2010) Mechanism of action of tin-containing fluoride solutions as antierosive agents in dentine: an in vitro tin-uptake, tissue loss, and scanning electron microscopy study. Eur J Oral Sci 118:376-384

10. Bartlett D, Sundaram G (2006) An up to 3-year randomized clinical study comparing indirect and direct resin composites used to restore worn posterior teeth. Int J Prosthodont 19:613-617

11. Gerrard WA, Winter PJ (1986) Evaluation of toothpastes by their ability to assist rehardening of enamel in vitro. Caries Res 20:209-216

12. Brunner E, Munzel U (2002) Nichtparametrische Datenanalyse (in German). Springer, Heidelberg

13. Schlueter N, Klimek J, Ganss C (2009) Efficacy of an experimental tin-F-containing solution in erosive tissue loss in enamel and dentine in situ. Caries Res 43:415-421

14. Lussi A, Schlueter N, Rakhmatullina E, Ganss C (2011) Dental erosion: an overview with emphasis on chemical and histopathological aspects. Caries Res 45(Suppl 1):2-12
15. Schlueter N, Neutard L, von Hinckeldey J, Klimek J, Ganss C (2010) Tin and fluoride as anti-erosive agents in enamel and dentine in vitro. Acta Odontol Scand 68:180-184

16. Vaidyanathan TK, Vaidyanathan J (2009) Recent advances in the theory and mechanism of adhesive resin bonding to dentin: a critical review. J Biomed Mater Res B Appl Biomater 88:558-578

17. Peumans M, De Munck J, Van Landuyt KL, Poitevin A, Lambrechts P, Van Meerbeek B (2010) Eight-year clinical evaluation of a 2-step self-etch adhesive with and without selective enamel etching. Dent Mater 26:1176-1184

18. Scherrer SS, Cesar PF, Swain MV (2010) Direct comparison of the bond strength results of the different test methods: a critical literature review. Dent Mater 26:e78-e93

19. Yoshida Y, Nagakane K, Fukuda R, Nakayama Y, Okazaki M, Shintani H, Inoue S, Tagawa Y, Suzuki K, De Munck J, Van Meerbeek B (2004) Comparative study on adhesive performance of functional monomers. J Dent Res 83:454-458

20. Fukegawa D, Hayakawa S, Yoshida Y, Suzuki K, Osaka A, Van Meerbeek B (2006) Chemical interaction of phosphoric acid ester with hydroxyapatite. J Dent Res 85:941-944

21. Vaidyanathan J, Vaidyanathan TK, Kerrigan JE (2007) Evaluation of intermolecular interactions of self-etch dentin adhesive primer molecules with type 1 collagen: computer modeling and in vitro binding analysis. Acta Biomater 3:705-714

22. Scott JE, Thomlinson AM (1998) The structure of interfibrillar proteoglycan bridges (shape modules) in extracellular matrix of fibrous connective tissues and their stability in various chemical environments. J Anat 192:391-405

23. Mazzoni A, Pashley DH, Ruggeri A Jr, Vita F, Falconi M, Di Lenarda R, Breschi L (2008) Adhesion to chondroitinase ABC treated dentin. J Biomed Mater Res B Appl Biomater 86:228-236

24. Helmerhorst EJ, Oppenheim FG (2007) Saliva: a dynamic proteome. J Dent Res 86:680-693

25. Schlueter N, Hardt M, Klimek J, Ganss C (2010) Influence of the digestive enzymes trypsin and pepsin in vitro on the progression of erosion in dentine. Arch Oral Biol 55:294-299 